\title{
Dairy Production System, Constraints and Opportunities in Ethiopia
}

\author{
Milkessa Gelana and Tamiru Abebe \\ Oromia Agricultural Institute, Bako Agricultural Research Center
}

\begin{abstract}
The literature review was conducted with the aim of compiling dairy cattle production system, main constraints and opportunities in Ethiopia. Based on their locations, there are three milk production systems; namely rural, peri-urban and urban milk production systems. Ethiopia has potential for dairy cattle production. Though Ethiopia has large dairy cattle population and favorable climatic conditions, self-sufficiency in milk production is low. The main constraints that affect milk production capacity of dairy cattle in Ethiopia includes feed shortage in terms of quality and quantity, land shortage for farming of improved forage, insufficient veterinary services, diseases, absence of improved breed, poor artificial insemination service, poor management of animals and lack of market-oriented production. So that, it is very important to introduce improved forage, increase AI utilization efficiency, and improve management practices and veterinary services. The finding of different authors conducted in different parts of the country indicated that the existence of large population of milk cows and diverse dairy animal's genetic resources, fast growing population, change in living standard and income growth of people, rabid urbanization, growing demand and indigenous knowledge in the preservation of milk and milk products, availability of trained manpower, existence of research institutions and technologies, existence of service providers such as veterinary health and artificial insemination centers, development of infrastructural sector like road access, water supply, communication activities were the key opportunities to dairy production. Generally, even though dairy sector constrained by many factors there are still ample opportunities for dairying. Therefore; coordinated activities must be done by respective bodies to minimize the identified constraints which hamper dairy development.
\end{abstract}

Keywords: Constraints, Dairy cattle, Ethiopia, Production system.

DOI: $10.7176 / \mathrm{JBAH} / 11-10-03$

Publication date:May $31^{\text {st }} 2021$

\section{BACKGROUND}

Agriculture is the most employment industry in the world it employed $42 \%$ of the worlds' population and more than $50 \%$ of developing countries population (Beyene et al., 2015). Livestock are the sub sector of agriculture. Like other developing countries, agriculture is main stay of Ethiopian economy. Ethiopia has the biggest livestock number that estimated 59.5 million cattle, 30.7 million sheep, 30.2 million goats, 8.43 million donkeys, 2.158 million horses, 0.409 million mules, 1.2 million camels, 59.49 million chicken and 5.90 million beehives (CSA, 216/17). In Ethiopia livestock contribute 30-40\% of Agricultural Growth Domestic Product (GDP), 16$20 \%$ of national GDP and 14-16\% of foreign exchanges (Bekuma et al., 2018). Livestock performs multiple functions in the Ethiopian household economy by providing crop production and soil fertility management, cash income and cash saved, fuel, social functions, and employments (USAID, 2010). FAO (2004) reported the average milk intake of Ethiopia is 17 liters per capital which is below estimated standard for African per capital consumption. PARI (2015) reported the average intake of milk of Ethiopia is 19 liters per capita which is below an estimated standard for African 40 liters per capita and well below the world average of 105 liters per capita consumption.

Ethiopia holds large potential for dairy development due to its large livestock population, the favorable climate for improved, high-yielding animal breeds, emerging market opportunity, improved policy environment for involvement of private sectors, and the relatively disease-free environment for livestock. Given the considerable potential for smallholder income and employment generation from high-value dairy products, development of the dairy sector in Ethiopia can contribute significantly to poverty alleviation and nutrition in the country (Gobena, 2016). Dairy sector is a major contributor to economic development especially among the developing countries. As an engine of growth, it provides increased income, employment, food and foreign exchange earnings as well as better nutrition (Bereda et al., 2014). Even though Ethiopia is home to the largest population of cattle in Africa, they are mostly maintained by smallholder, commercial and pastoral farmers; and more than $99 \%$ are indigenous low yielders that greeneries a high gap between demand and supply of milk and milk products. Despite the existing high potential for dairy development due to huge livestock resources, conducive climatic conditions and urbanizations, the performance of the dairy industry in Ethiopia has not been encouraging when evaluated against even the dairy performance of Eastern African countries (Galmessa et al., 2013). The annual growth rate in cow milk production reported in 1990 in Ethiopia was nearly 1\% as opposed to $6.2 \%$ in East Africa and $3.3 \%$ in the whole of Africa. 
So far, most of the characterization reviews were limited to state farms located mainly in higher altitudes where the climate is suitable for milk production. As dairy production in Ethiopia is constrained by several factors; there are a number of challenges and bottlenecks limiting the success and profitability of household dairy production systems in Ethiopia. Therefore, a comprehensive literature review on the current status of dairy production system and its constraints and opportunities in the country is mandatory. Therefore, the current review is aimed with the objectives of the following;

- $\quad$ To undertake literature review on dairy production system in Ethiopia

- To review on constraints of dairy productions in Ethiopia

- To assess the existing Opportunities of dairy production in Ethiopia

\section{LITERATURE REVIEW}

\subsection{Dairy production systems in Ethiopia}

In Ethiopia, dairy production is one of the subsectors of livestock production that contributes to the live of the owners through important sources of food and income; even though dairying has not been fully exploited and promoted in the country (Beyene et al., 2015). Like most dairy production systems found in the tropics, the Ethiopia dairy production system includes large number from small to large sized and subsistence to market oriented farms (Bereda et al., 2014). Though different classifications have been used to characterize the dairy production system in the country; based on their locations, Ahimed et al. (2003) classified into three broad categories, namely, urban, peri-urban and rural dairy production.

\subsubsection{Rural household dairy production system}

The highest source of milk in Ethiopia is traditional dairy cattle production while cattle are kept for drought power without giving any focus to improve the milk production potential of the dairy cattle and focuses on butter production rather than fluid milk (Alemayehu et al., 2012). Most dairy farmers in Ethiopia are widely dispersed in rural areas while majority of dairy markets are in urban areas. Due to highly perishable nature of dairy products and its potential to transmit zoonotic disease and other pathogens and toxins, it is difficult for dairy farmers to exchange in urban markets (Bekuma et al., 2018). Thus, a whole chain approach is basically needed, which includes education of consumers. Unless milk and milk products find a market outlet, they are retained for household consumption and the level of production is kept low (Seifu and Tassew, 2014). Over 85\% of the milk produced by rural households is consumed within the producer households with the proportion marketed being less than 7\% (Bereda et al., 2014). From the total national milk production, $97 \%$ from rural milk production system which is produced by smallholders. The rural milk production system is highly reliant on the low productivity of the indigenous zebu cattle breeds that can produce 400-680 liters of milk per cow per lactation period. Pastoralists, agro-pastoralists and mixed crop-livestock producers are grouped under the rural dairy cattle production system (Gebresellasie, 2019).

\subsubsection{Per-urban or small scale dairy production system}

The peri-urban dairy cattle production systems are mainly located at the edge of the town areas which have comparatively better access to urban centers in which dairy cattle products are extremely wanted (Tegegne et al., 2013). This production system is categorized as semi-intensive crop-livestock farming system. Because of steadily increasing demand in milk consumption, peri-urban dairy farms are growing around cities and towns (Galmessa et al., 2013). Most of the dairy cattle producers depend on hybrid cows and they practiced supplementary concentrate feeding (Gebresellasie, 2019). It possesses animal types ranging from $50 \%$ crosses to high grade Friesian in small to large sized farms, and contributed only $2 \%$ of the total milk production of in Ethiopia. This sector owns most of the country's improved dairy stock (Gobena, 2016). As related to the rural dairy cattle production system, peri-urban dairy cattle production systems is typically located along roads within reasonable distance to urban centers and keepers are involved in fluid milk market (Nigatu et al., 2012).

\subsubsection{Urban or commercial dairy production system}

In most towns of Ethiopia, the urban dairy cattle production systems are practiced with little or no land resources for the production and sale of milk. It is the most market oriented dairy cattle production system compared to other production systems (Bekele et al., 2015). Urban areas producers use crossbred, as well as high grade, dairy animals. However, only $1 \%$ of the dairy cattle from the total population of dairy cattle of the country are kept under urban dairy cattle production system (Gezu and Zelalem, 2018). Cattle are housed in improved shelters made of locally available materials. Concentrates, roughages and non-conventional feeds are the main feed resources which are used in urban dairy cattle production system. Moreover, road side grazing, fruits of plants and wastes also used in urban dairy cattle production system (Gurmessa et al., 2015). Under the use of intensive management system urban dairy cattle production systems has better access to inputs and services providing by the public and private sectors as compared to other dairy cattle production systems (Gebresellasie, 2019, Gobena, 2016). They have also access to animal health services, use more intensive systems. Milk is sold to consumers and processing plants through informal market. But milk supply is low due small number of dairy cattle population kept under this system (Gurmessa et al., 2015). Generally, the urban and peri-urban dairy cattle 
production systems use improved dairy cattle or hybrid cows with relatively better management, purchased and conserved feed and stall-feeding. As a result cows shows the better performance and highly profitable as compared to other systems (Gebresellasie, 2019).

\subsection{Constraints of dairy production in Ethiopia}

The constraints of dairy cattle production differ with in the three production systems and among different locations (Kassa, 2019). As indicated by Gebresellasie (2019) high feed cost, land shortage and space limitation, feed quality, availability and cost problems as well as inadequate extension and veterinary services were the major dairy production system constraints in the Urban and Peri-Urban areas of central Highlands of Ethiopia. Bereda et al. (2014) also reported that land shortage, feed shortage, water shortage and poor artificial insemination efficiency (AI) service as the most important dairy production constraints. Similarly, feed shortage and land scarcity, diseases, poor access to market place, restricted market information, lack of improved breed, inadequate artificial insemination (AI) and infrastructure were reported as the primary constraints of dairy cattle production by Gemechu and Amene (2017). The major production problems listed by Misganaw et al. (2017) includes absence of milk processing plants and equipment's, lack of skills, inadequate manufacture space, changeable marketing scheme, shortage of water, poor genetic potential of dairy cows for milk production.

\subsubsection{Animal diseases}

Adequate reproductive performance of the lactating herd is a major component of profitability in dairy farms. Improved reproduction shortens the transition from being a primiparous to becoming a multiparous cow leading to increments in milk yield, increases the average milk yield per day of calving interval by reducing the days in milk of the lactating herd, increases the number of replacement animals available, influences culling decisions, and accelerates the rate of genetic progress. On the contrary, animal diseases negatively influence production and reproduction in dairy cows (Santos and Ribeiro, 2014). Livestock disease is one of the challenging issues for dairy development in the country. The problem is further exacerbated with the either absence or insufficient veterinary services (Galmessa et al., 2013). Among fourteen identified common animal diseases by Mersha et al. (2019), trypanosomiasis $(82.65 \%)$ ranked first, blackleg $(60.75 \%)$ ranked second and internal and external parasites $(54.9 \%)$ ranked the third respectively and cause major production losses in the study areas.

\subsubsection{Feed shortage}

Livestock feed resources are classified as natural pasture, crop residue, improved pasture and forage, agro industrial by products, other by-products like food and vegetable refusal, of which the first two contribute the largest feed type (Alemayehu, 2003). Understanding type of feed resources and its nutritional quality are important for improving production and productivity for enhancing food security. Dairy productivity is the function of nutrition, health status and genetic potential of the animal. Among these factors, nutrition plays the most important role as it represents the major cost dairy production. Seasonal inadequacy of the quantity and quality of available feeds are the major problems facing dairy cattle production. Additionally the efficiency with which the available feed is utilized is constrained by failure to use recommended management practices that could improve dairy output (Gobena, 2016). Dietary nutrition plays a substantial role in any dairy development and the best appearance of genetic potential for milk production depends on satisfactory supply of nutrients. Dietary nutrients favor the metabolic pathways that empower the animal to catch up its genetic potential. The, nutrients (minerals, vitamins, carbohydrate, proteins and fat) are equally important as imbalances or deficiencies of one or more of these nutrients barricade the production, productivity and health status (Gezu and Zelalem, 2018). In Ethiopia, dairy cattle are chiefly fed on crop residues, natural pasture (grazing and/or hay), different agro-industrial, and locally available by-products as supplementary feeds. Such feeds are often lacking adequate macro and micro mineral concentrations (Bekele et al., 2019). According to the study conducted by Beyene et al. (2015); feed shortage, livestock disease and market are the common problems in dairy production in the study area. Feed usually based on fodder and grass are either not available in sufficient quantities, or when available, are of poor nutritional quality. These constraints result in low milk and meat yields, high mortality of young stocks, longer parturition intervals and low animal weights (Galmessa et al., 2013). Feed shortage in terms of quality and quantity is the major constraint regardless of the dairy Production system and agro-ecology (Gobena, 2016).

\subsubsection{Shortage of land}

Most urban producers (97\%) keep their cattle within their own residence compound. Although urban expansion creates great opportunity for commercialization of dairy production, it has to be supported with appropriate policy framework to promote dairy development (Gobena, 2016). Milk production is constrained primarily by shortage of land for grazing and cultivation of improved forage crops. The problem of feed shortage is associated with small land holdings to produce sufficient quantities and limited knowledge on the conservation of seasonally available feed (Bereda et al., 2014). According to study conducted by Mersha et al. (2019) the major livestock production constraints described by respondents was animal feed and grazing land shortage ranked first $(82.15 \%)$. 


\subsubsection{Breed related constraints and reproductive wastage}

The amount of daily milk production has direct relationship with the number of crossbred cows available in particular area (Galmessa et al., 2013). In Ethiopia, indigenous cattle breeds are the dominant source of milk and milk products. The number of crossbred cows is very low and is mainly concentrated in and around major urban and per-urban centers. Indigenous cattle breeds are generally characterized as multi-purpose animals and managed in low input production system. These animals have been naturally selected for adaptive and not for functional traits, and they are inherently low milk producers (Tegegne et al., 2013). Genetics make up of our dairy cattle covers about $99 \%$ of the cattle populations in Ethiopia are indigenous that are adapted to feed and water shortages, diseases challenges and harsh climates. The productivity of indigenous cattle believed to be poor even if no practical recording scheme has been used to judge their merit (Ahimed et al., 2003) (Table1).

Table 1. Some production and productive performances of cattle

\begin{tabular}{|c|c|c|c|c|}
\hline Location/ Towns & \multicolumn{3}{|c|}{ Daily milk yield per liter per cow } & Lactation length in months \\
\hline Local & Dairy & Local & & Dairy \\
\hline Ambo & $3.3(0.51)$ & $7.8(1.0)$ & $8.7(1.0)$ & $9.9(1.0)$ \\
\hline Baddalle & $2.2(0.5)$ & $4.0(1.5)$ & $7.5(0.9)$ & $9.8(1.8)$ \\
\hline Dambi Dollo & $2.2(0.4)$ & $6.8(0.7)$ & $9.6(1.0)$ & $11.1(1.4)$ \\
\hline Gimbi & $1.2(0.3)$ & $6.0(2.3)$ & $10.1(0.6)$ & $10.3(0.2)$ \\
\hline Jimma & $2.1(0.6)$ & $9.3(0.9)$ & $9.5(1.2)$ & $10.2(1.0)$ \\
\hline Mattu & $1.9(0.4)$ & $5.0(2.3)$ & $7.5(0.7)$ & $13.0(3.6)$ \\
\hline Naqamte & $2.8(0.3)$ & $6.9(0.8)$ & $8.8(0.7)$ & $10.6(0.9)$ \\
\hline Overall & $2.2(0.4)$ & $6.5(1.5)$ & $8.8(0.8)$ & $10.7(1.4)$ \\
\hline
\end{tabular}

- Values in the parenthesis are standard deviations

Source: Galmessa et al., 2013.

\subsubsection{Poor access to inputs and services}

Access to inputs and services includes extension, animal health, credit, market information, AI and dairy inputs. The inefficient AI service reported in the current study is associated with lack of sufficient facilities and trained AI technicians in the area. AI service in Ethiopia has not been successful to improve reproductive performance of the country's dairy industry (Sinishaw, 2005). The inefficient AI service reported in the current study is associated with lack of sufficient facilities and trained AI technicians in the area (Bereda et al., 2014). The others major livestock production constraints were ranked by Mersha et al. (2019) as animal health and veterinary service related problem $(81.04 \%)$, absence of improved breeds $(52.54 \%)$, awareness or knowledge gab among the farmers (49.78\%), drinking water shortage and impurity (42.74\%) and market problem (41.45\%).

\section{Opportunities of Dairy production in Ethiopia}

The large population of dairy cows, diverse genetic resource of dairy cattle adapted to the varied environment, and different agro-ecological zone, presence of potential land for manufacturing of quality feeds under rain season and irrigated environments are opportunities for milk producers to increase milk production (Tegegne et al., 2013). The existence of fast growing population and urbanization with an extended utilization of milk and its products are the main opportunities of milk production in Ethiopia (Kassa, 2019). This is agreed with the result of indicated that fast urbanization, increase population number and modification in economic standard of the individuals, dairying gives an opportunity to the dairy producers to generate income as it is highly demanded product. The growing demand for milk and its products like fermented milk (Yogurt), butter, cottage cheese, butter milk, ghee and whey offers a good opportunity for dairy producers (Gebreselassie, 2019). Hence a potentially large domestic market is the main opportunities of milk production in Ethiopia (Kassa, 2019). The existence of diverse agro ecologies coupled with diverse flora species rendered in the different parts of the country to have native knowledge in the conservation of milk and its products in the dairy farming system using various sources of herbs. There are plenty of opportunities for dairy development listed by (Gebreselassie, 2019). were high demand for milk and its products consumption, enormous humanoid population with long lasting custom of utilization of milk and its products, fast rate of migration from rural to urban areas and revenue growing, accessibility of skilled manpower, the existence of research center organizations and technologies, existence of service providers such as veterinary health and artificial insemination (AI) centers, and employment creation. On the other hand, development of infrastructural sector, such road access or road construction to connect towns with kebeles, water supply, electrification, communication activities would favor modern dairying (Gemechu and Amene, 2017).

\section{DISCUSSION}

The Ethiopia dairy production system includes large number from small to large sized and subsistence to market oriented farms. Based on climate, landholdings and integration with crop production criteria, three production systems are recognized in Ethiopia. Among the existing production systems, the traditional dairy production 
systems, is the one involving from smallholder dairy farms (Bereda et al., 2014). Based on their location rural milk production, puri-urban and urban milk productions are the three main milk production system classifications in Ethiopia (Gebresellasie, 2019). According to this review, the major supplementary feed of livestock was crop residue which accounts for about $89.38 \%$ and $18.99 \%$ for the dry and wet seasons of the year, respectively. The result of the current review agrees with the sample survey report that indicates the major sources of feed for livestock in sedentary production were natural pasture grazing $57.13 \%$, crop residue $29.29 \%$, Hay 7.24\% and byproducts $1.17 \%$ (Beyene et al., 2015) and a study report from Gurage zone of south western Ethiopia where grazing covers $56.7 \%$ and $16.7 \%$ supplementary feed was crop residues which implies that major feed supplement was crop residue (Bereda et al., 2014).

The types of feed and feed resources reported in this current review were also in agreement with the previous studies of which indicated that dairy activities are highly constrained by feed shortage. Shortage of land was especially emphasized by the urban dairy producers (Bekele et al., 2015). However; shortage of feeds, livestock disease and poor management practice, poor genetic improvement and lack of organized marketing system are the major constraints that hinder the profitable production of livestock in Ethiopia (Bekuma et al., 2018). According to Beyene et al. (2015), 138(77.10\%) of the respondent were ranked feed as a high shortage. Livestock diseases were ranked the 2nd problem in dairy production. 174(97.2\%) were ranked marketing the third issues in dairy production. The study conducted by Galmessa et al. (2013) showed feed shortage, livestock disease and market are the common problems in dairy production in the study area. $77.1 \%, 75.4 \%$ and $96.655 \%$ of the respondent ranked feed shortage; livestock disease and market are the top ranked three constraints respectively (Beyene et al., 2015).

\section{CONCLUSION}

A compressive literature review was made with the objectives of reviewing dairy production system in the Ethiopia and its major constraints. The dairy production system in the Ethiopia is categorized into three broad categories based on their locations, as urban, peri-urban and rural dairy production. From the current literature review, feed shortage in terms of quality and quantity, land shortage and space limitation, inadequate extension and veterinary services, diseases, poor market data (internal and external), absence of better quality breed, insufficient infrastructure and inadequate artificial insemination (AI) services, poor management of animals, lack of market-oriented production were the primary as constraints of dairy production. Generally, with the existing problems there are many opportunities for dairy development in Ethiopia. Therefore, coordinated efforts are necessary to address the identified constraints across the different dairy production systems.

\section{RECOMMENDATIONS}

- Feed availability is low both in quality and quantity hence strong extension service on use of concentrate feed, grazing land management system, and development and utilization of improved forage is very important.

- Diseases are among the major constraints; therefore, dairy owners should be trained with good management practices and the government should expand enough veterinary services and better health care.

- It is important to use AI service to increase milk production by improving genetic potential of local dairy cattle.

- It is important to use modern production system with improved technology in urban area and in rural area

\section{Conflict of interest}

The authors declare that there is no conflict of interest.

\section{REFERENCES}

Ahimed, M. M., Ehui, S. and Asefa, Y. (2003). Dairy development in Ethiopia. ILRI, International Livestock Research Institute. Socio-economics and policy Research Working Paper, 58.

Alemayehu, M. (2003). Country pasture/Forage resources profiles: Ethiopia. FAO, 2003.

Alemayehu, N., Hoekstra, D. and Tegegne, A. (2012). Smallholder dairy value chain development: The case of Ada'a District, Oromia Region, Ethiopia. Nairobi: ILRI.

Bekele, A., Fekadu, B. and Mitiku, E. (2015). Handling, processing and marketing of cow milk in urban and peri urban area of Dangila Town, Western Amhara Region, Ethiopia. Global Journal of Food Science and Technology.

Bekele, W., Goshu, G., Tamir, B., Demissie, T., Sahle, Z. (2019). Characterization of Dairy Production Constraints, Existing Feeding Practices and Mineral Supplementation in Dairy Feeds in Two Districts of East Shoa Zone, Ethiopia. J Adv Dairy Res 7(1), 219. 
Bekuma, A., Galmessa, U. and Fita, L. (2018). Dairy Products Marketing Systems and its Constraints in Gimbi District, West Wollega Zone, Oromia, Ethiopia. J Vet Sci Technol 9, 556. doi:10.4172/2157-7579.1000556.

Bekuma, A., Wahid, M., Ahmed, Fita, L. and Galmessa, U. (2018). Study on Dairy Production System and Its Constraints in Gimbi District, West Wollega Zone, Oromia, Ethiopia. Global Veterinaria, 20 (5), 215-224. DOI: 10.5829/idosi.gv.2018.215.224.

Beyene, B., Hundie, D. and Gobena, G. (2016). Assessment on Dairy Production System and its Constraints in Horoguduru Wollega Zone, Western Ethiopia. Sci. Technol. Arts Res. J., 4(2): 215-221.

Bereda, A., Yilma, Z. and Nurfeta, A. (2014). Dairy Production System and Constraints in Ezha Districts of the Gurage Zone, Southern Ethiopia. Global Veterinaria, 12 (2), 181-186, $2014 . \quad$ DOI: 10.5829/idosi.gv.2014.12.02.81199.

Central Statistical Agency (CSA) (2016/17). Agricultural sample survey, federal democratic republic of Ethiopia report on livestock and livestock characteristics. http://www.csa.gov.et/surveyreport/ category/355-eth-agss2017? download=871:report-on-areaand- production-of-major-crops-2010-meher-season.

FAO (Food and Agricultural Organization), (2004). Food and Agricultural organization Livestock sector brief livestock information, sector analysis and policy branch, Rome.

Galmessa, U., Dessalegn, J., Tola, A., Shiv, P. and Kebede, L. M. (2013). Dairy Production Potential and Challenges in Western Oromia Milk Value Chain, Oromia, Ethiopia. Journal of Agriculture and Sustainability, 2 (2013), 1, 1-21.

Gebreselassie, L. (2019). Review on Dairy Production System, Constraints and Opportunities in Ethiopia. Journal of Scientific and Innovative Research, 8(4), 108-111.

Gemechu, T. and Amene, T. (2017). Dairy cattle milk production, handling, processing, utilization and marketing system in Bench Maji Zone, Southwest Ethiopia, 8(9), 158-167. DOI: 10.5897/IJLP2017.0381.

Gezu, T. and Zelalem, Y. (2018). Dairy Trade in Ethiopia: Current Scenario and Way Forward-Review. Dairy and Vet Sci J., 8(1), 555728. DOI: 10.19080/JDVS.2018.08.555728.

Gobena, M. M. (2016). Household Dairy Production System, Marketing and Constraints in Ethiopia. Journal of Marketing and Consumer Research, 29, 2016.

Gurmessa, K., Tolemariam, T., Tolera, A., Beyene, F. and Demeke, S. (2015). Feed Resources and Livestock Production Situation in the Highland and Mid Altitude Areas of Horro and Guduru districts of Oromia Regional State, Western Ethiopia. Science, Technology and Arts Research Journal, 4(3), 111-116.

Kassa, A. (2019). Review of performance, marketing and milk processing of dairy cattle production system in Ethiopia. J Dairy Vet Anim Res. 2019; 8(1), 1-9. DOI: 10.15406/jdvar.2019.08.00234.

Mersha, T., Bekele, D., Mideksa, T. and Gelana, M. (2019). Assessment of Major Production Constraints and Common Diseases of Cattle in Selected Districts of East Wollega Zone, Western Ethiopia. Journal of Biology, Agriculture and Healthcare, 9 (11), 2019, DOI: 10.7176/JBAH.

Misganaw, G., Hailemariam, F., Mamo, D., Tajebe, S. and Nigussie, Y. (2017). Production Potential, Challenges and Prospects of Dairy Cooperatives in Aksum and Adwa Towns, Ethiopia. J Dairy Vet Anim Res 5(6), 00165. DOI: 10.15406/jdvar.2017.05.00165.

Nigatu, A., Dirk, H. and Tegegne, A. (2012). Smallholder dairy value chain development: The case of Ada'a woreda, Oromia Region, December 2012, pp-7.

Program of Accompanying Research for Agricultural Innovation (PARI) Ethiopia, 2015. Available at h t $\mathrm{t} \mathrm{p} \mathrm{:} \mathrm{/} \mathrm{/}$ w w w . w o r l d w i d e extension.org/africa/ethiopia/s-ethiopia.

Santos, J.E.P. and Ribeiro, E.S. (2014). Impact of animal health on reproduction of dairy cows. Department of Animal Sciences, University of Florida, Gainesville, FL, USA. Anim. Reprod., 11 (3), 254-269.

Seifu, E. and Tassew, A. (2014). Small-scale milk processing, utilization and marketing of traditional dairy products in Bahir Dar Zuria and Mecha districts, northwestern Ethiopia. Journal of Food Technology Research, 1, 122-132.

Sinishaw, W. (2005). Study on semen quality and field efficiency of AI bulls kept at the National Artificial Insemination Center. M.Sc. Thesis presented to school of graduate studies of Addis Ababa University, Faculty of Veterinary Medicine Debre Zeit, Ethiopia.

Tegegne, A., Gebremedhin, B., Hoekstra, D., Beyene, B. and Yosef, M. (2013). Smallholder dairy production and marketing systems in Ethiopia: IPMS experiences and opportunities for market-oriented development. https://cgspace.cgiar.org/handle/10568/27914.

USAID (Unite State of America peoples Aid), (2010). The Next stage in Dairy Development for Ethiopia Dairy Value Chains, End Markets and Food Security; Cooperative Agreement 663-A-00-05-00431-00;Addis Ababa, Ethiopia.

Yilma, Z., Guernebleich, E. and Sebsibe, A. (2011). A Review of the Ethiopian Dairy Sector. 